\title{
Neuroprotective Effects Of D-Penicillamine In The Neonatal Period: Case Reports
}

\author{
Lajos Lakatos* \\ Department of Pediatrics, University of Debrecen, Hungary
}

*Corresponding author: Lajos Lakatos, Department of Pediatrics, Faculty of Medicine, University of Debrecen, Hungary

\begin{abstract}
D-penicillamine (D-PA) was first used as a potential benefit for neonatal hyperbilirubinemia (NHBI) caused by hemolytic diseases of the newborn infant or immaturity of UDP-glucuronyltransferase enzyme. In this time there was a remarkedly low incidence of retinopathy of prematurity (ROP) in the infants treated with D-PA. Later, our studies were replicated in other institutes in Hungary, Poland, the USA, India and Mexico. It is important to note that there was no intolerance or short- or long-term toxicity of the medication, in spite of the fact that D-PA was used 10-20 times higher doses in the newborn period, than those in adult age. To our concept, the bilirubin-induced neurologic dysfunction (BIND), ROP and Autism Spectrum Disorders (ASD) are neurodegenerative and neurodevelopmental diseases (NDs) of immature brain caused by accumulation of free metals, unconjugated bilirubin (UCB), and UCB-Cu complex (as prooxidant), respectively, in the basal ganglia (BG) and other relevant parts of the central nervous system (CNS). The main cause is the hemolysis of neonatal red blood cells producing a great amount of heavy metals (mainly iron and copper) which are inducing reactive oxygen species (ROS). These elements can be find in the bloodstream, and pass through the immature blood-brain-barrier (BBB). In addition, ROS contribute to increased BBB permeability creating a dangerous vitious circle in the neonatal brain.
\end{abstract}

Keywords: D-Penicillamine In the Neonatal Period; Orphan Drug; Copper Hypothesis of BIND; ROP and ASD; Follow-Up Studies

\section{Introduction}

A recent report by the National Research Council found that " $50 \%$ of all pregnancies in the US are now resulting in prenatal or postnatal mortality, significant birth defects, developmental neurological problems, or otherwise chronically unhealthy babies. The incidence of neurotoxic or immune reactive conditions such as autism, schizophrenia, Attention Deficit Disorder (ADD), dyslexia and learning disabilities have been increasing rapidly in recent years" [1]. In the body, misplaced iron and copper ions serve as catalysts to initiate and accelerate oxygen radical activity. The interaction between an oxygen radical and its target produces a cascade of free radicals. Left unchecked, they will in turn attack and disrupt nearby cells that will also produce torrents of additional free radicals, and also so on [2,3]. Free radicals and related reactive species are drawning towards copper and iron ions [4]. They attack cells in the vicinity, disrupting cell membranes, enzymes systems, neurotransmitters, and neuroreceptors. Neuro-systems are particularly susceptible to peroxidative destruction because of their high concentration of fat insulation. D-PA can maintain cellular health by reducing free radical pathology by removing the metal ions (especially copper and iron) that are the catalists for lipid peroxidation [5].

\section{Has it been tested or proven already?}

This is a monotonous oft-repeated criticism against D-PA treatment. Although a number of qualified physicians have practiced chelation in the neonatal period safely and effectively in Hungary, Poland, the US, India [6-14] and other foreign countries during the last forty years, traditional medicine continues to refuse it. When sufficient time has elapsed to fully evidence its importance, someone can say: Yes, surely it is important, but it no longer new. Since it has been declared by FDA that it is an orphan drug $[15,16]$ the intravenous D-PA is not available in the drug market. "An orphan drug is a pharmaceutical agent developed to treat medical conditions which, because they are so rare, would not be profitable to produce without government assistance. The conditions are referred to as orphan diseases". Question: are neonatal disorders - BIND, ROP, ASD, ADD et cet. - rare i.e. orphan diseases?? Chowrimooto et al. [17], more than 20 years ago, pointed out that: "fetal copper metabolism is different from that of the adult ....with 
apparent similarity to Wilson's disease." This apparent similarity to Wilson's disease has led to the suggestion that in this disease there is a failure to change from the neonatal mode of copper metabolism to the adult mechanism. In both Wilson's disease and the normal fetus biliary copper excretion is greatly reduced, with low plasma copper and absent or low plasma caeruloplasmin concentrations.

\section{Case Reports}

\section{Case 1}

In the Figure 1 the first patient can be seen who received D-PA treatment in the neonatal period [18]. This girl was an AB0incompatible preterm infant (birthweight: 2200 g.). Because of serious hemolysis, an early exchange transfusion was required, but not even this intervention was able to stop the rapid increase in the bilirubin level. At the beginning of the second exchange, cardiopulmonary arrest occurred requiring resuscitation. At an extremely high bilirubin level $(32.5 \mathrm{mg} / \mathrm{dl})$ and with symptomes of acute bilirubin encephalopathia, intravenous administration of D-PA was begun. The first dose caused a spectacular fall of $6.5 \mathrm{mg} /$ $\mathrm{dl}$ in the bilirubin level in 4 hours, and under the influence of such treatment we were able to witness a gradual disappearance of the hyperbilirubinemia. She is now a member of a famous operhouse in Germany as an opera singer. This case is all the more remarcable as the most common sequelae of NHBI is the sensoneural hearing impairment.

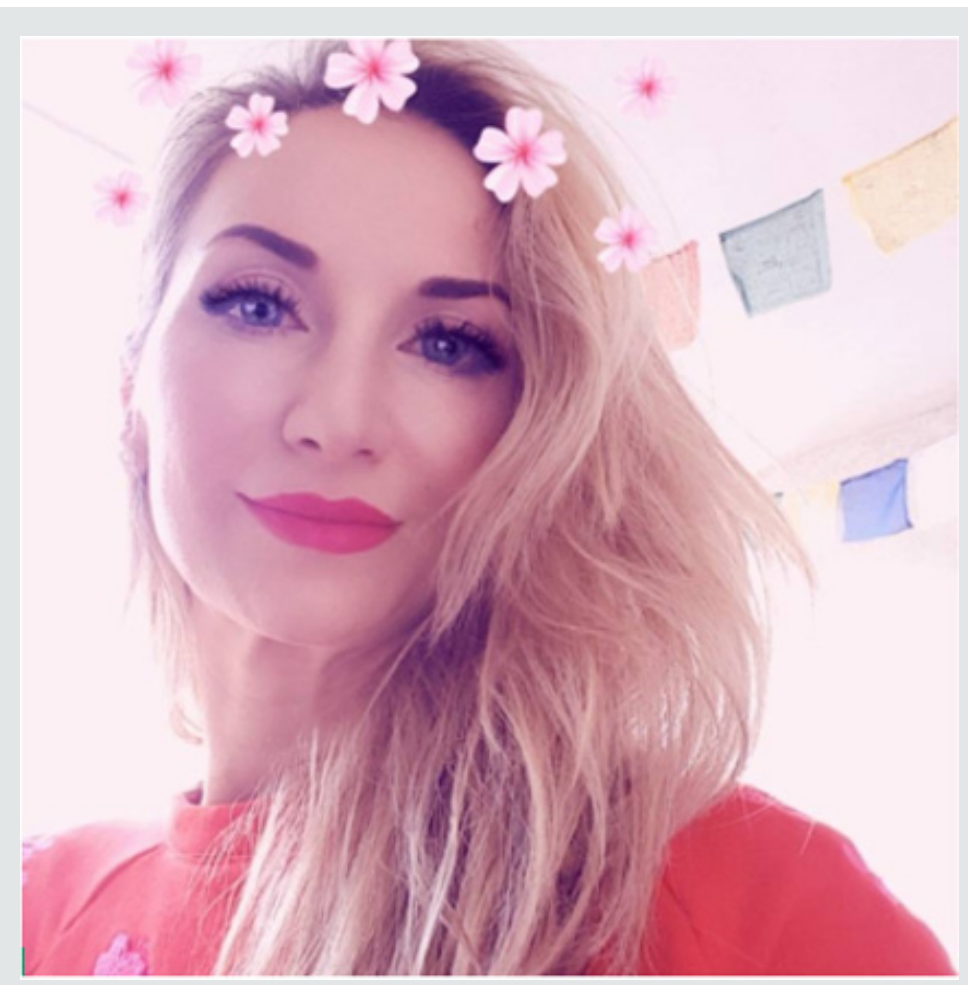

Figure 1: The first patient (she is now (and here) 46 years old - with permission).

\section{Case 2}

We have cared for a term infant girl who was born at 39 weeks' gestation to a 24-year-old, blood group 0 , Rh-positive mother. The pregnancy was uncomplicated, and the group A, Rh-positive baby weighed $3100 \mathrm{gm}$. At 50 hours of age, the bilirubin level (Sebi) was $416 \mathrm{mmol} /$ liter $(24.3 \mathrm{mg} / \mathrm{dl})$; the hemoglobin $(\mathrm{Hb})$ value was $130 \mathrm{~g} /$ liter. The baby was transferred to our neonatal unit, and we decided to perform an exchange transfusion. At the time of admission the parents, belonging to the Jehovah's Witness sect, signed a request in the chart expressing their wish that blood not be administered under any circumstances. However, they authorized us to apply the alternative therapies of orally administered DPA (300 mg/kg per day, divided in three doses for 3 days), phototherapy (Phth), intravenous fluids, and recombinant human erythropoietin (rhEPO). The latter was started on day 7 at $200 \mathrm{U} /$ $\mathrm{kg}$ subcutaneously and was given on every second day until day 23, supplemented with vitamin E, folic acid, and iron. The clinical characteristics of the infant with ABO-HDN are shown in [19]. It is interesting that she has also an excellent voice (she was the winner in a school song festival at 16 years old), and she is the best student in mathematics.

\section{Case 3 When the exception proves the rule}

Elevated copper levels threaten human health and can cause ASD.

http://dx.doi.org/10.1155/2011/385767

http://autism-genetic-risk-factor.blogspot.hu/2008/11/arechildren-with-autism-heterozygous.html

http://autism-genetic-risk-factor.blogspot.hu/2008/11/ifgenetic-risk-factor-for-autism-is.html

https://www.ncbi.nlm.nih.gov/pubmed/23823984/

http://barbfeick.com/healing_autism/chapters/Copperheads. html 
http://www.conem.org/2013/07/the-role-of-zinc-andcopper-in-autism-spectrum-disorders/

https://www.academia.edu/4079689/The_Role_of_Zinc_and_ Copper_in_Autism_Spectrum_Disorders

http://www.autismweb.com/forum/viewtopic.php?p=196145

http://autism-genetic-risk-factor.blogspot.hu/2008/11/manychildren-with-autism-have-high.html

\section{https://www.naturalhealth365.com/copper_levels.html/}

The high copper level significantly increases the prevalence of NDs, including ASD. Although the 24-hour urine copper test is inconsistent in the neonatal period, and the normal value range may vary among different laboratories, the penicillamine challenge test has proved itself to be useful in the detection of high copper in the urine. This test widely used in the diagnosis of Wilson's Disease which is a mitochondrial disorder that causes encephalopathy and depletes metallothionein. And "patients with Wilson's disease have relevant glutathione depression, with low levels of reduced glutathione and cysteine and high concentrations of oxidized glutathione [just like many children with autism]". [Table 1. - third link]. For those children who are voiding copper more than usually, high doses DPA therapy is necessary for 2 - 3 weeks. As I mentioned above our concept was conceived because of long-term follow-up we found only 1 ASD in the children and adults who were treated with DPA in their neonatal period ( $\mathrm{N}=550$ patients so far). The 30 years old male patient was born as a premature infant and had a serious hyperbilirubinemia. He was treated with D-PA without success, because exchange transfusion was necessary.

Table 1: Clinical Data of the Reported Infant.

\begin{tabular}{|c|c|c|c|}
\hline Postnatal Age & $\begin{array}{c}\text { Sebi }(\boldsymbol{\mu m o l} / \mathbf{d}) \\
\text { liter } \mathbf{m g} / \mathbf{d l})\end{array}$ & $\mathbf{H b}(\mathbf{g} / \mathbf{l i t e r})$ & Treatment \\
\hline 50 hours & $416=24.3$ & 130 & DPA + Phth \\
\hline 58 hours & $354=20.7$ & & DPA + Phth \\
\hline 76 hours & $277=16.2$ & & DPA + Phth \\
\hline 100 hours & $233=13.6$ & 115 & \\
\hline 7 days & $214=12.5$ & 113 & rhEPO \\
\hline 9 days & & 95 & rhEPO \\
\hline 12 days & & 87 & rhEPO \\
\hline 15 days & & 98 & rhEPO \\
\hline 20 days & & 101 & rhEPO \\
\hline 25 days & & 120 & \\
\hline 6 months & & 125 & \\
\hline
\end{tabular}

\section{Conclusion}

Heavy metal ions, especially copper and iron play a pivotal role in the pathogenesis of neurodegenerative diseases including BIND or other neonatal conditions, having impact on both protein structure (misfolding) and oxidative stress. Our recently published long-term follow-up studie [20] and other healthy and highly educated patients' (they are now 28 to 46 years old) suggest that D-PA administration to the newborn infants may have significant neuroprotective effects in cases jeopardized by BIND or ROP. Copper dyshomeostasis and oxidative stress have also been concerned in neurodegenerative/neurodevelopmental disorders such as ASD or ADD. Our recommendation: all newborns should be screened for ASD, particularly the premature babies (especially the very low birthweight infants -VLBW) and infants suffering from NHBI. These conditions significantly increase the prevalence of NDs, including ASD and ADD. Although the 24 hour urine copper test is inconsistent in the neonatal period, the Penicillamine challenge test may be useful in the detection of higher copper in the urine. For those children who are voiding copper more than usually in the given institutes or laboratories, high doses of D-PA therapy is necessary for 2 to 3 weeks. Our concept was conceived because of long-term follow up ( 3 to 46 years) we found only 1 ASD in the children and adults who were treated with D-PA in their neonatal period ( $\mathrm{N}=550$ patients so far; - There is indeed an increased incidence of ASD worldwide. "New Prevalence Numbers for 2018: 1 in 59 US Children have autism" [21], and it is most common among boys. Copper is implicated directly or indirectly in the pathogenesis of a large number of neurological diseases including ASD.

\section{References}

1. Boyle MM, Beaty G (2010) How Heavy Metals Affect Neurotransmitters Production and Balance.

2. Perrone S, Tataranno ML, Stazzoni G, Buonocore G (2012) Oxidative stress and free radicals related diseases of the newborn. Adv Biosci Biotechn 3: 1043-1050.

3. Martinez A, Reina M (2017) Copper or free radical scavenger? Computat Theoret Chem 1104: 1-11.

4. Jomova K, Valko M (2011) Advances in metal-induced oxidative stress and human disease. Toxicology 283: 65-87.

5. Ayala A, Munoz MF, Argüelles S (2014) Lipid Peroxidation: Production, Metabolism, and Signaling Mechanisms of Malondialdehyde and 4-Hydroxy-2-Nonenal. Oxid Med Cell Long 360438.

6. Lakatos L, Kover B (1974) Az ujszulottkori hyperbilirubinaemiak D-Penicillamin terapiája. (D-Penicillamine Therapy In The Neonatal Hyperbilirubinaemias.) A Preliminary Report.Orv Hetil (Hungarian J Med) 115: 307-311.

7. Lakatos L, Kover B, Oroszlan G, Vekerdy Z (1976) D-Penicillamine Therapy in AB0 Hemolytic Disease of the Newborn Infant. Europ J Pediat 123: 133-137.

8. Koranyi G, Kovacs J, Voros I (1978) D-Puenicillamine treatment of hyperbilirubinemias of preterm infants. Acta Paediatr Acad Sci Hung 19: 9-14.

9. Nagy A, Felszeghi E (2000) Per os D-Penicillaminnal és fototerápiával sikeresen kezelt Rh-isoimmunisation. Gyermekgyógyászat 51: 81-83.

10. Rokicki W (1989) D-Penicylamina-nowy lek w profilaktyce I terapii noworodka? (D-Penicillamine -A New Drug For Prevention And Treatment In Neonates. Polish -Przeg Ped 19: 229-233.

11. Christensen RD, Alder SC, Richards SC, Lambert DK, Schmutz N (2007) D-Penicillamine administration and the incidence of retinopathy of prematurity. J Perinatol 27: 103-111.

12. Tandon M, Dutta S, Dogra MR, Gupta A (2010) Oral D-penicillamine for theprevention of retinopathy of prematurity in very low birth weight infants: a randomised, placebo-controlled trial. Acta Paediatrica 99: 1324-1328.

13. Phelps DL, Lakatos L, Watts JL (2001) D-Penicillamine for preventing retinopathy of Prematurity. Cochrane Database Syst Rev (1): CD001073. 
14. Qureshi MJ, Kumar M. (2013) D-Penicillamine for preventing retinopathy of prematurity in preterm infants. Cochrane Database Syst Rev (9): CD001073.

15. Hadjivasiliou, Andreas (2015). EvaluatePharma® Orphan Drug Report 3rd Edition.

16. Lakatos L (2019) Not only orphan illnesses exist! - The intravenously administered D-penicillamine in the neonatal period can greatly reduce the incidence of BIND, ROP, ASD, and may be the Ebola and HIV vertical infections. Phab Linx Journal of Pediatrics and Child Health Care Synopsis.

17. Chowrimootoo GFE, Scowcroft H, Seymour CA (1998) Caeruloplasmin isoforms in Wilson's disease in neonates. Arch Dis Child 79: F198-F201.
18. Lakatos L, Kövér B, Péter F (1974) D-Penicillamine therapy of neonatal hyperbilirubinaemia. Acta Paediatr Acad Sci Hung. 15: 77-85.

19. Lakatos L, Csathy L, Nemes E (1999) "Bloodless" Treatment of a Jehovah's Witness Infant With ABO Hemolytic Disease. J Perinatol 19: 530-532.

20. Pataki I, Balla G, Nagy A, Berkes A, Szőlős A, et al. (2018) Long-term Follow-up of patients treated with D-Penicillamine in the neonatal period. Neonatal Biol 7: 1-12.

21. https://tacanowblog.com/2018/04/26/autism-rate-1-in-59-kids-itstime-to-care/

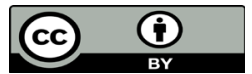

This work is licensed under Creative Commons Attribution 4.0 License

To Submit Your Article Click Here:

Submit Article

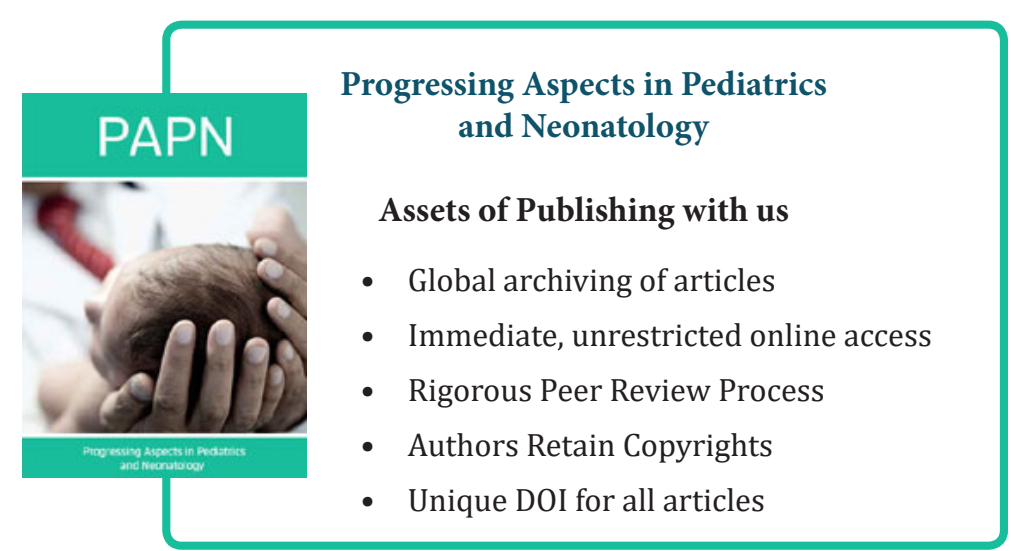

